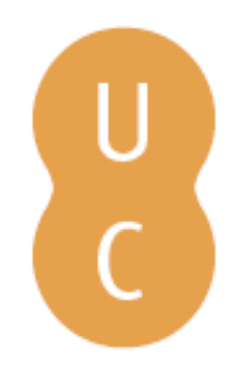

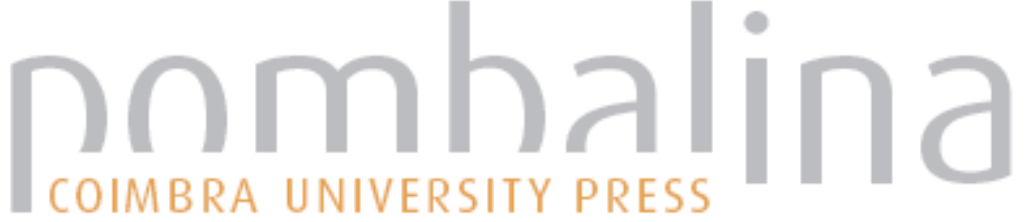

\section{Impacto de temperaturas extremas na mortalidade e morbidade - um estudo na ilha da Madeira}

\author{
Autor(es): $\quad$ Gomes, Ricardo; Brites, Rafael \\ Publicado por: Imprensa da Universidade de Coimbra; RISCOS - Associação \\ URL \\ persistente: URI:http://hdl.handle.net/10316.2/34882 \\ DOI: $\quad$ DOI:http://dx.doi.org/10.14195/978-989-96253-3-4_81 \\ Accessed : $\quad$ 26-Apr-2023 06:09:11
}

A navegação consulta e descarregamento dos títulos inseridos nas Bibliotecas Digitais UC Digitalis, UC Pombalina e UC Impactum, pressupõem a aceitação plena e sem reservas dos Termos e Condições de Uso destas Bibliotecas Digitais, disponíveis em https://digitalis.uc.pt/pt-pt/termos.

Conforme exposto nos referidos Termos e Condições de Uso, o descarregamento de títulos de acesso restrito requer uma licença válida de autorização devendo o utilizador aceder ao(s) documento(s) a partir de um endereço de IP da instituição detentora da supramencionada licença.

Ao utilizador é apenas permitido o descarregamento para uso pessoal, pelo que o emprego do(s) título(s) descarregado(s) para outro fim, designadamente comercial, carece de autorização do respetivo autor ou editor da obra.

Na medida em que todas as obras da UC Digitalis se encontram protegidas pelo Código do Direito de Autor e Direitos Conexos e demais legislação aplicável, toda a cópia, parcial ou total, deste documento, nos casos em que é legalmente admitida, deverá conter ou fazer-se acompanhar por este aviso. 

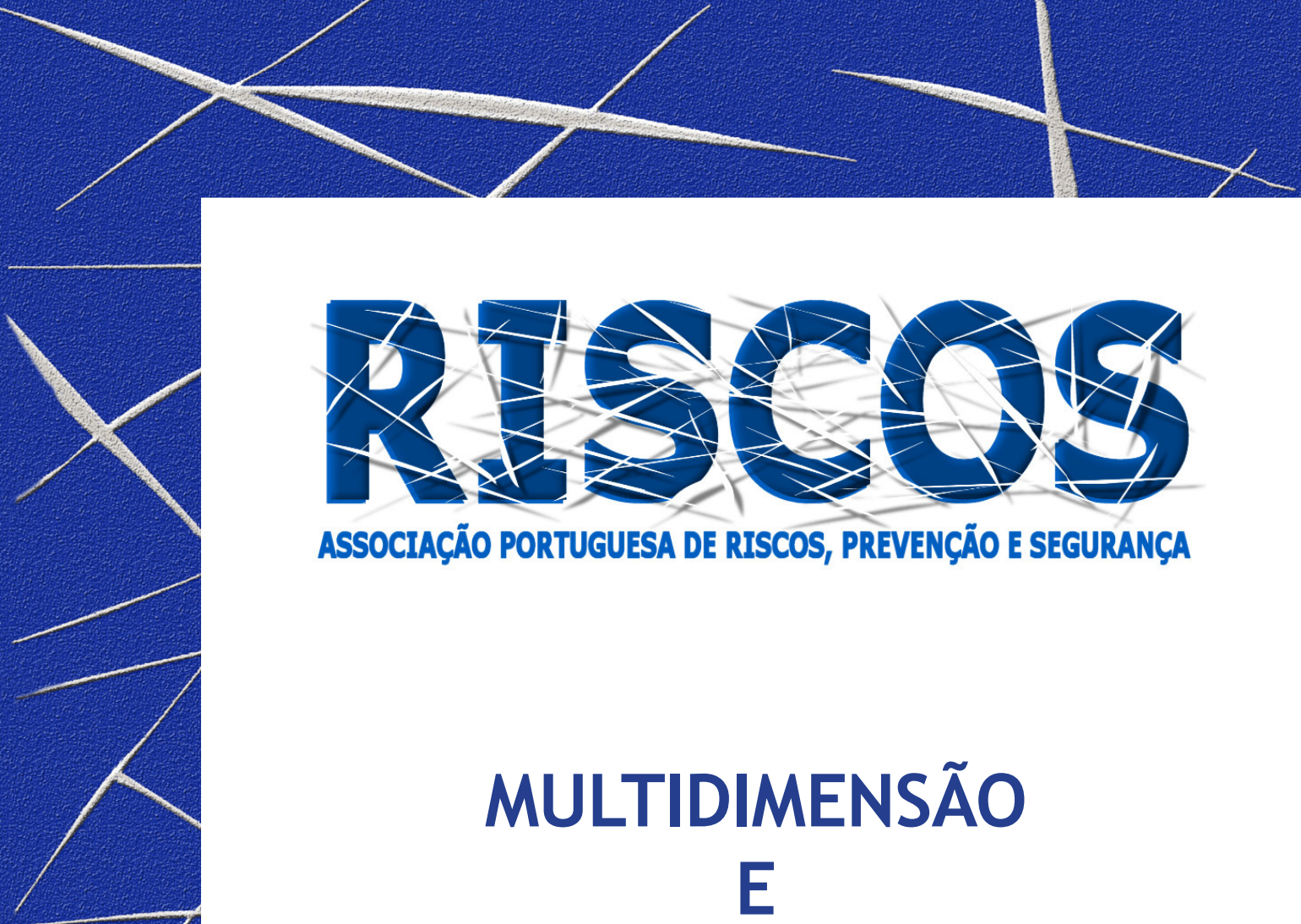

ASSOCIAÇÃO PORTUGUESA DE RISCOS, PREVENCCÃO E SEGURANÇA

MULTIDIMENSÃO

E
TERRITÓRIOS DE RISCO

III Congresso Internacional

I Simpósio Ibero-Americano

VIII Encontro Nacional de Riscos

Guimarães

2014 


\title{
IMPACTO DE TEMPERATURAS EXTREMAS NA MORTALIDADE E MORBIDADE - UM ESTUDO NA ILHA DA MADEIRA
}

\author{
Ricardo Gomes \\ Serviço Regional de Proteção Civil, IP-RAM \\ ricardo.gomes@procivmadeira.pt \\ Rafael Brites \\ Serviço Regional de Proteção Civil, IP-RAM \\ rafael.brites@procivmadeira.pt
}

\begin{abstract}
RESUMO
A relação entre ondas de calor e efeitos fisiológicos associados a temperaturas extremas, que se refletem num acréscimo de mortalidade e aumento de admissões nas urgências hospitalares, tem sido demonstrada em diversos estudos realizados tendo por referência Portugal Continental, o mesmo não sucedendo relativamente à ilha da Madeira, uma lacuna que se pretendeu colmatar.

Identificaram-se períodos de calor particularmente intenso, entre 2002 e 2013, com base nos índices Heat Index, Índice Diaz e Índice Ondas e confrontou-se com o registo diário de óbitos e o registo diário de admissões no serviço de urgência do Hospital Dr. Nélio Mendonça para o mesmo período. Compararam-se os valores de óbitos e admissões de urgência registados nos períodos de calor intenso com os valores médios para o mesmo período, entre 2002 e 2013, de forma a identificar variações nos fenómenos da mortalidade e morbidade, particularmente em determinados grupos etários (65 ou mais anos).

Palavras-chave: Índice Ondas; Heat Index; Índice Diaz; Mortalidade; Morbidade;
\end{abstract}

\section{Introdução}

Diversos estudos relativos a Portugal Continental evidenciaram a relação entre momentos de calor particularmente intenso - e dias seguintes, e variações mais ou menos significativas ao nível da mortalidade e morbidade da população, particularmente entre os mais idosos, associados a todas as causas, bem como relativamente a patologias respiratórias e circulatórias (Calado et al, 2003; Paixão e Nogueira, 2003; Almeida et al, 2010; Monteiro et al, 2013). Estes estudos utilizam diferentes metodologias para identificar os períodos de maior desconforto térmico, utilizando diferentes variáveis e diferentes índices, nomeadamente o Heat Index, Índice Diaz e Índice Ondas (Diaz, 2004; Monteiro, et al. 2012; Monteiro et al, 2013).

Com este trabalho pretendeu-se efetuar uma primeira análise exploratória da relação entre períodos de maior calor e a variação da mortalidade diária e da afluência ao serviço de urgências hospitalares. Pretende-se identificar variações nos fenómenos da mortalidade e morbidade, particularmente em determinados grupos etários (65 ou mais anos) nos períodos de maior calor bem como nos dias subsequentes.

\section{Método}

Neste estudo a área em análise circunscreve-se aos concelhos de Câmara de Lobos, Funchal e Santa Cruz, concelhos contíguos que reúnem 74\% da população da ilha da Madeira (INE, 2011). Identificaram-se os períodos de calor particularmente intenso, entre 2002 e 2013, com base nos índices Heat Index, Índice Diaz e Índice Ondas (Diaz, 2004; Monteiro, et al. 2012; Monteiro et al, 2013). Para tal utilizaram-se dados relativos a Temperatura e Humidade Relativa do Ar da Estação Meteorológica do Observatório Meteorológico do Funchal (58 metros de altitude). 
Relativamente aos períodos de calor selecionados, e aos 5 dias seguintes, identificou-se o número de óbitos e o registo diário de admissões no serviço de urgência do Hospital Dr. Nélio Mendonça (Funchal) para o mesmo período. Os dados relativos aos óbitos foram disponibilizados pelo INE, tendo sido facultados apenas dados relativamente a óbitos diários por todas as causas e óbitos diários por todas as causas na classe etária de 65 e mais anos. Os dados relativos às urgências hospitalares foram disponibilizados pelo Serviço de Estatística do Hospital Dr. Nélio Mendonça. Os registos com identificação do diagnóstico segundo a Classificação Internacional de Doenças apenas existem para o ano de 2013 e parte do ano de 2012. Assim, considerando o período em análise, 2002-2013, utilizaram-se os registos de admissão nas urgências e, em particular, as admissões devido a 'Doença súbita'.

Compararam-se os valores diários de óbitos e óbitos na classe etária de 65 ou mais anos e de admissões de urgência devidas a 'Doença súbdita', individualizando também aqui a classe etária de 65 e mais anos, nos períodos de calor selecionados, e nos 5 dias seguintes, com os valores esperados. Estes, foram definidos através do cálculo da média diária para os meses de julho, agosto, setembro e outubro, excluindo os períodos de calor em análise. Os quatro meses selecionados correspondem aos que possuem, de acordo com as Normais Climatológicas, valores mais elevados de Temperatura Média, Temperatura Média Máxima e Temperatura Média Mínima para a estação meteorológica do Observatório Meteorológico do Funchal.

\section{Resultados}

Em agosto de 2003 registaram-se na estação meteorológica do Observatório Meteorológico do Funchal valores condizentes com existência de 3 períodos de calor, um segundo o Índice Ondas, outro segundo índice Diaz e outro segundo o Heat Index. Entre 12 e 16 de agosto de 2003 houve uma sobreposição destes períodos. Nestes 4 dias houve um acréscimo ao nível de óbitos de 33\%, e de óbitos na classe etária de 65 ou mais anos de $9 \%$, comparativamente aos valores médios de referência. Relativamente a admissões nas urgências devido a doença súbita, houve uma diminuição de $11 \%$ quer no total, quer relativamente a pacientes com 65 ou mais anos, comparativamente com os valores esperados. Considerando apenas os 5 dias subsequentes ao período de calor, houve também um aumento do número de óbitos de $9 \%$, e de óbitos na classe etária dos 65 ou mais anos de 18\%. Também neste caso as admissões no serviço de urgências devido a doença súbita diminuíram $14 \%$ e no caso de pacientes com 65 ou mais anos diminuíram $17 \%$, comparativamente aos valores esperados.

Entre 24 e 27 de julho de 2004 registaram-se na estação meteorológica do Observatório Meteorológico do Funchal valores condizentes com existência de um período de calor, quer segundo o índice Diaz, quer segundo o Heat Index. Nesses 4 dias houve um acréscimo de óbitos de $42 \%$ relativamente aos valores esperados e aumento de $46 \%$ de óbitos na classe etária de 65 ou mais anos. Relativamente a admissões no serviço de urgências devido a doença súbita, houve uma diminuição de $8 \%$ relativamente ao valor diário de referência e uma diminuição de $2 \%$ considerando pacientes com 65 ou mais anos. Contabilizando apenas os 5 dias subsequentes ao período de calor, houve um aumento do número de óbitos de $40 \%$ e acréscimo de óbitos na classe dos 65 ou mais anos de $48 \%$. As admissões no serviço de urgência diminuíram $8 \%$ e, no caso de pacientes com 65 ou mais anos, diminuíram $18 \%$.

Seguindo-se ao período de calor de julho de 2004, houve em agosto desse mesmo ano novo período de calor. Entre os dias 26 e 31 de agosto registaram-se na estação meteorológica do Observatório Meteorológico do Funchal valores condizentes com existência de um período de 
calor, quer segundo o índice Diaz, quer segundo o Heat Index, quer de acordo com o índice Ondas. Nesses 6 dias houve um decréscimo ao nível de óbitos de $26 \%$ e um ligeiro aumento de óbitos na classe de 65 ou mais anos de $7 \%$ comparativamente aos valores de referência. Relativamente a admissões no serviço de urgências devido a doença súbita, houve uma diminuição de $15 \%$ no total e uma redução de $27 \%$ contabilizando pacientes com 65 ou mais anos. Considerando os 5 dias subsequentes ao período de calor, houve uma diminuição do número de óbitos de $16 \%$ e também uma diminuição de óbitos na classe dos 65 ou mais anos de $41 \%$. As admissões no serviço de urgências devido a doença súbita diminuíram $20 \%$ e, no caso de pacientes com 65 ou mais anos, diminuíram $28 \%$.

Em 2006 ocorreram períodos de calor segundo os índices Diaz e Heat Index que se sobrepuseram entre os dias 4 e 6 setembro. Nesses 3 dias houve um acréscimo de óbitos de $43 \%$ e um aumento de óbitos na classe etária de 65 ou mais anos de $56 \%$. Relativamente a admissões nas urgências devido a doença súbita, houve um aumento residual de $2 \%$ no total e uma diminuição de $14 \%$ relativamente a pacientes com 65 ou mais anos. Nos 5 dias subsequentes ao período de calor, houve um aumento do número de óbitos de 19\% e também aumento de óbitos na classe dos 65 ou mais anos de $27 \%$. As admissões no serviço de urgências devido a doença súbita aumentaram $3 \%$ e, no caso de pacientes com 65 ou mais anos, aumentaram $2 \%$.

Em agosto e setembro de 2012 ocorreram 2 períodos de calor segundo índice Diaz, ambos com duração de 4 dias. No primeiro destes períodos, entre 22 e 25 de agosto, houve um acréscimo de óbitos de $24 \%$ e um aumento de óbitos na classe etária de 65 ou mais anos de $35 \%$. Relativamente a admissões no serviço de urgências devido a doença súbita, houve uma diminuição de $17 \%$ no total e aumento de $6 \%$ pacientes com 65 ou mais anos. Nos 5 dias subsequentes ao período de calor, houve um aumento residual do número de óbitos de $4 \%$ e um aumento de óbitos na classe etária dos 65 ou mais anos de $23 \%$. As admissões no serviço de urgências devidas a doença súbita diminuíram $8 \%$ e, no caso de pacientes com 65 ou mais anos, aumentou $8 \%$

No segundo destes períodos de 2012, 3 semanas depois, entre 15 e 19 de setembro, houve uma diminuição significativa quer de óbitos, quer óbitos na classe etária de 65 ou mais anos para cerca de metade. Relativamente a admissões no serviço de urgências devido a doença súbita, houve uma diminuição de $12 \%$ no total e não houve variação quanto a pacientes com 65 ou mais anos. Considerando os 5 dias subsequentes ao período de calor, houve uma pequena diminuição de óbitos e um residual aumento de óbitos na classe etária de 65 ou mais anos. As admissões no serviço de urgências devido a doença súbita diminuíram $6 \%$ e, no caso de pacientes com 65 ou mais anos aumentaram $18 \%$.

\section{Conclusão}

Nos seis períodos identificados como particularmente quentes, bem como nos 5 dias subsequentes, registaram-se variações ao nível da mortalidade associada a todas as causas, no total e relativamente à classe etária 65 ou mais anos, bem como nas admissões no serviço de urgências. Estas variações foram mais significativas no que se refere a óbitos, em particular na classe etária 65 ou mais anos, e prolongaram-se quer pelos períodos quentes, quer pelos dias seguintes.

Identificaram-se dois padrões distintos. Nos períodos de 2003, julho de 2004, 2006 e agosto de 2012 verificou-se um aumento significativo do número de óbitos, bem como de óbitos na classe etária de 65 ou mais anos acompanhado por diminuição de admissões no serviço de urgências. 
Nos 5 dias seguintes ao período quente manteve-se o acréscimo de óbitos, particularmente significativo neste caso nos óbitos da classe etária de 65 ou mais anos.

Nos períodos de agosto de 2004 e setembro de 2012, ambos antecedidos semanas antes por outros períodos quentes com significativo aumento do número de óbitos em relação ao esperado, registou-se pelo contrário significativa redução do número de óbitos, que se prolongou quer pelo período quente, quer pelos dias seguintes, e afetou tanto o número de óbitos total como na classe etária 65 ou mais anos.

\section{Bibliografia}

Almeida, S.; Casimiro, E. e Calheiros, J. (2010) - Effects of apparent temperature on daily mortality in Lisbon and Oporto, Portugal. Environmental Health. 9(12), Harvard, p. 1-7.

Calado, R.; Botelho, J.; Catarino, J. e Carreira, M. (2003) - Mortalidade em Portugal no Verão de 2003: influência das ondas de calor. Ministério da Saúde - Direção Geral da Saúde. P. 1-10.

Diaz J. (2004) - Análisis de tendencias en olas de calor a partir de series largas de temperatura. In IV Congresso de la Asociación Espanola de Climatologia - El clima entre el mar y la montaña. Santander: Asociación Española de Climatología. p. 347-354.

INE (2011) - Censos 2011. Resultados definitivos-Região Autónoma da Madeira. XIV Recenseamento Geral da População e IV Recenseamento Geral da Habitação, Instituto Nacional de Estatística, Lisboa.

Monteiro, A. et al., (2012) - Atlas da saúde e da doença - vulnerabilidades climáticas e socioeconómicas na Grande Área Metropolitana do Porto e Concelho do Porto. Suporte digital. Volumes I e II.

Monteiro, A.; Carvalho, V.; Velho, S. e Sousa, C. (2013) - The accuracy of the heat index to explain the excess of mortality and morbidity during heat waves - a case study in a mediterranean climate. Bulletin of geography. Socio-economics Series. 20(2013), Tórun, p.71-84.

Paixão, E. e Nogueira, P. (2003) - Efeitos de uma onda de calor na mortalidade. Revista Portuguesa de Saúde Pública. 21(1), Elsevier, p.41-54. 